This mode of instruction was adopted by the Professor, as one by far to be preferred to the horrible alternative, by which, to become at length safe operators hereafter, junior practitioners must qualify themselves, at the imminent hazard of the lives of their fair clients, and of their own reputation, by experimental trials with the forceps upon the living bodies of their patients.

That the reflection which has, by Professor Murphy, been cast upon the memory of his predecessor in the chair, is entirely without foundation, and therefore unjust, I can further truly maintain, from my personal knowledge of what he did in his practice during twelve years, up to his lamented decease in December, 1841, and from direct information which $I$ have from one who can speak to his practice from the year 1814 . From that source $I$ learn, that in three-fourths of the cases to which he was requested to bring his forceps, he had either found them unnecessary,-a further trial of the natural powers, or a judicious treatment, other than instrumental, in certain cases of a depletive kind; sometimes the simple use of the catheter for the relief of the bladder, or the exhibition of a clyster, having brought the labour speedily and satisfactorily to a conclusion,--or, Nature being unequal to her task, by reason of deficiency of space, the power in question was absolutely contraindicated, and therefore not employed, in consequence of impaction of the presenting head.

It was always, my informant adds, a source of great pleasure to him, which he never failed strongly to express, when he had been able, dexterous as he was in their use, to dispense with his instruments, (a.dexterity which he told me he had taught himself by diligent practice on the machines, and not npon the bodies of his patients, ) from that wholesome dread which he felt, and all should feel, against their unnecessary employment. It was ever a prominent principle with him, which he never failed to impress upon me, as well as upon all his pupils, that, to the performance of an operation, the prevention of it by a well-timed patience, or by a judicious and timely appeal to medical treatment, was infinitely to be preferred.

As bearing somewhat upon the subject of these remarks, I might direct atten'ion 'to the fact, that my late father deprived Dr. Denman's definition of a natural labour, of its Iimitation as to time; namely, that it should not exceed twenty-four hours. Denman's restriction of a natural labour to a limited time, although applying to the majority of cases, my father maintained, did not hold good with regard to a great number, especially of first labours, completed with perfect safety to the tissues and lives interested in the function, beyond the above time, by different periods. The chief motive which the Professor had in this alteration, besides greater accuracy as to fact, was his belief that the idea of a prescribed time being considered essential in the definition of a natural labour, might lead to a reliance less upon Nature than upon the mechanical powers of our art to officions and meddlesome practice; so much was he, in truth, an admirer of Nature's resources.

Not only is it rigidly true that my father, so far from being habitually fond of, or bold in, the use of instruments, was most guarded in his practice, example, and teaching, in that respect, but it is known to me as an interesting fact, that the first event which aroused his especial and earnest attention to midwifery and the improvement of obstetric instruments, so that they might be more safely employed, was an extensive injury inflicted on the person of his own and eldest child, by the use of an instrument exhibiting the faults which the Professor afterwards removed, and that in the hands of a gentleman of a good and a well-earned fame.*

The protracted duration and the unfortunate results of several of the early operations which he had witnessed, after the commencement of his practice of midwifery in London, although, in some instances, conducted by gentlemen who had acquired reputation as obstetricians, tended still more to encourage my father in his undertaking.

Now although Professor Davis introduced what have been very generally considered great improvements in the construction of instruments, and diligently applied himself to the framing of rules and precautions for their safe employment, he did not by any means pay a principal attention to instrumental midwifery; he had accomplished his entire object re. lating to that department, considerably prior to the year 1825, during the whole of which time, however, as a lecturer, his attention was fairly and impartially distributed over the different parts of a midwifery course.

His further exertions were directed to other points of ob-

* My father had not then practised midwifery, and consigned the care of his wife in this her first confinement to his friend, in whose good manage. ment he felt great confidence. stetric practice. He was the first (1819) to depart from the dangerous doctrine propounded by Rigby, on the management of unavoidable hæmorrhage, and the first in this country to point out and urge the correct principle of the plug, its indications, and its twofold intention. His lectures on uterine hremorrhage during pregnancy, in the early and in the latter months, were extended to a considerable length, and excited a deep interest in his hearers. His descriptions of puerperal convulsions, puerperal phrenitis, and insanity, with his illustrative cases from his own abundant experience, were so graphically given, that we, one and all of us, felt as though transported at the time to the bedside of the patient.

He was the first to ascertain the true pathology of phleg. masia dolens, its dependence upon phlebitis, and the correct treatment founded upon it. The first case, that of Caroline $\mathrm{D}$ - was investigated in March, 1817, " Obstet. Med.," Art., Phlegmasia Dolens, and formed the subject of a debate at the Bartholomew Society in the same year. Other cases occurred subsequently, presenting precisely the same appearances, under my father's personal cognizance, and one of which he received the particulars from his friend Mr. Oldknow, of Nottingham. The descriptions of these cases, which finally confirmed the accuracy of his view, appeared in his paper, which was heard with great interest at one of the mcetings of the Medico-Chirurgical Society, and published in the twelfth volume of its "Transactions." That the attention of the late professor was earnestly and successfully directed to other departments of obstetric medicine, was apparent from the very numerous attendance upon his lectures throughout each course, and from the valuable store of practical information contained in his large work on obstetric medicine, published in 1836 .

Although he was considered dexterous as an operator, in the few cases where an operation was called for, he was not less esteemed for his powers of diagnosis, and the accuracy and acuteness of his judgment under circumstances in practice the most trying and perplexing.

In the remarks which $I$ have thus made upon the opinion expressed by. Dr. Murphy on the professional practice and teaching of his predecessor, the only object which I have had, in view has been the performance of an act of strict justice to. the memory of my late parent and teacher, a tribute which I feel confident will be most readily and willingly paid to him by the many who attended his prelections, or sought his assistance amidst the doubts, the dangers, and the difficulties, of their midwifery practice.

Russell-place, Fitzroy-square, 1846.

\section{ON THE TREATMENT OF HAEMORRHAGE FROM LEECH-BITES.}

By F. L. Gervis, Esq., Surgeon, Tiverton.

VARIous methods have been proposed, in THe Lavodr, for checking hæemorrhage arising from leech-bites. I will mention the applications I have found most useful in my practice; whenever excessive hæmorrhage has occurred from such a cause, which have proved effectual in arresting it. In a case which lately fell under my care, where I had occasion to apply leeches to the throat, for an attack of cymanche tonsillaris in a young lady, one leech fastened over the external jugular vein, which bled so profusely, that I was sent for in great haste, The blood was streaming from the puncture, which I endeavoured to stop by dossils of lint successively applied, and adhesive plaster, at the same time keeping up a firm pressure on the part with my finger. This plan was unsuccessful, and without delay, I dipped the lint in a strong solution of alum, and placed it on the puncture. In a few minutes the hæmorrhage ceased. Not long since, a patient came to my surgery, very faint and exhausted, from loss of blood. A tooth had been extracted on the previous day, and he had bled during the whole of the night. On examining the socket of the tooth, I found that a small artery had been divided, and the hæmorrhage still continued without intermission. I applied lint, dipped in spirits of turpentine, to the part, which, in general, is an excellent styptic; but it proved quite ineffectual in checking the bleeding. I then had recourse to the alnm lotion, and within two minutes it was completely arrested. The other remedy I recommend for checking hæmorrhage from leech-bites is the tobacco used for smoking. This is so efficacious, that it only requires a trial to be generally adopted, when the usual means fail. I have known various applications fail until the tobacco has been tried, and this with complete success.

Tiverton, Feb. 1846. 